\title{
Approaches to the Management of Humanitarian Aid in the Era of Globalization
}

\author{
Jozef Kubás ${ }^{1, *}$ and Juraj Fabuš ${ }^{2}$ \\ ${ }^{1}$ University of Zilina, Faculty of Security Engineering, Department of Crisis Management, \\ Univerzitna 1, 01026 Zilina, Slovakia \\ ${ }^{2}$ University of Zilina, Faculty of Operation and Economics of Transport and Communications, \\ Department of Communication, Univerzitna 1, 01026 Zilina, Slovakia
}

\begin{abstract}
.
Research background: Humanitarian aid is about people trying to help the victims of crises. The needs of the victims of humanitarian crises are crucial for the provision of humanitarian aid. That is why this aid is an integral part of globalization also contributes to the deepening of relations between donors and recipients around the world.

Purpose of the article: The purpose of the article is to point out the humanitarian aid provided and financed by the Slovak Republic. This expenditure will compare with the expenditure of the other members of the European Union. For a higher informative value, attention will be focused also on the comparison of EU states and Slovakia in terms of per capita.

Methods: The scientific methods used in the article will be, in particular, to compare EU Member States' humanitarian aid expenditure over a last period. Analysis and synthesis be use throughout the solution of the article. Using these methods, the connections and relationships between the facts will be examined. Inductions and deductions will be used to interpret the results correctly.

Findings \& Value added: The result of the article will be a clear presentation and comparison of the Slovak and EU funds spent on humanitarian aid for a certain period. The results will make it possible to understand the importance of this assistance in the context of globalization. A comparison of the per capita conversion is an important basis for a realistic picture of aid with regard to possible capacities.
\end{abstract}

Keywords: humanitarian aid; crisis management; globalization; European Union

JEL Classification: $F 35 ; H 84$

\footnotetext{
*Corresponding author: jozef.kubas@,fbi.uniza.sk
} 


\section{Introduction}

The issue of humanitarian crises is very topical. In today's society there are a number of threats that negatively affect the environment of states. Various negative events can cause a humanitarian crisis. In the event of such a crisis, individual states do not have the necessary resources to deal with it. That's why other states contribute in the form of humanitarian aid to other states or regions that need this aid. Humanitarian aid is enshrined in laws, generally binding legislation and various documents. Organizations, institutions, communities are governed by international humanitarian law when providing humanitarian aid.

Humanitarian aid has a tradition of solidarity and consists in people trying to help the victims of crises. Its goal is to save lives and provide immediate assistance to people in need. In the beginning, international humanitarian aid provided increased emphasis on its principles, quality and professionalism. However, humanitarian actors currently face many specific challenges. Humanitarian crises are becoming more frequent and their effects are becoming more severe. They are related to various changes, the changing nature of conflicts, the growing competition for various strategic resources, extreme poverty, poor public administration, but also the failure of states.

The civilian population, especially from developing countries, is their main victim. There is a growing tendency to ignore or flagrantly violate humanitarian and international law. Interventions in the "humanitarian space" adversely affect access to vulnerable groups and the security and protection of humanitarian workers, which are two basic preconditions for the delivery of humanitarian aid [1].

\section{Methodology}

During the preparation of the article, we performed an analysis of the literature dealing with the same or similar issues. We paid the greatest attention to articles included in the prestigious Web database from Science. These articles have the required quality and contain information that has allowed us to understand some of the links. Subsequently, we focused on the comparison of allocated funds from individual states of the European Union. For the sake of comparison, we have recalculated these funds per capita in the state that provided this assistance. We also tried to find out the dependence between the provided aid and the economic maturity of the state. For such a comparison, we focused on the GDP of the countries and recalculated it per capita too.

In order to know whether there is a dependence between the funds spent and the GDP of individual countries, we used a correlation function that examines the dependence in 2019. The correlation coefficient can take values from the interval $<-1,1>$ "if the correlation coefficient is equal to 0 , it means that there is no relationship between the investigated quantities. If it is equal to one, then the quantities are directly dependent on each other, an increase of one quantity causes an increase of the other, if it is equal to -1 , an increase of one quantity causes a decrease of the other quantity. Table 1 shows the interpretation of the values of the correlation coefficient [2].

$$
\text { Correl }(X, Y)=\left[\sum(\mathrm{x}-\overline{\mathrm{x}})(\mathrm{y}-\overline{\mathrm{y}})\right] /\left[\sum\left(\sqrt{ }(\mathrm{x}-\overline{\mathrm{x}})^{2}\right) \sum(\mathrm{y}-\overline{\mathrm{y}})^{2}\right]
$$


When $\mathrm{x} \in$ Amount provided Humanitarian aid per capita

y $C$ GDP per capita in PPS

and $\overline{\mathrm{x}}, \overline{\mathrm{y}}$ are string value AVERAGE $\mathrm{x}$ and $\mathrm{y}$

Table 1. Interpretation of correlation coefficient values. [2]

\begin{tabular}{|c|c|}
\hline The value of the correlation coefficient & Interpretation \\
\hline 0,90 do $1,00(-1,00$ do $-0,90)$ & very high correlation \\
\hline 0,70 do $0,90(-0,90$ do $-0,70)$ & high correlation \\
\hline 0,50 do $0,70(-0,70$ do $-0,50)$ & medium correlation \\
\hline 0,30 do $0,50(-0,50$ do $-0,30)$ & low correlation \\
\hline 0,00 do $0,30(-0,30$ do 0,00$)$ & very low or no correlation \\
\hline
\end{tabular}

It was important to focus on Slovakia. From the point of view of humanitarian aid through analysis and synthesis, we focused on funding to affected countries and funding by sector.

\section{Results}

\section{The European Union as an organization of international crisis management in resolving humanitarian crises}

Crisis management is an interdisciplinary scientific discipline that deals with management as a purposefully oriented activity of people. Its mission is to create a management methodology with an emphasis on achieving the effectiveness of this activity in relation to the target stated, i.e. protection the mankind the material values and environment against the effects of the crisis phenomena during the time we are overcoming them. It has a coordination character; it unifies and directs people of various occupations. Last, but not least, the crisis management is a managing activity of people who fulfil the management functions in a specific environment different from the common administrative and manufacturing environment. It is also the mastery to be able to solve concrete crisis phenomena and to select corresponding approaches in concrete conditions [3].

The importance of crisis prediction is unquestionable. One of the features of crises and crisis situations is the lack of time and information, which places high demands on managers and decision-makers. These requirements for the readiness of people in specific positions and for the decision-making process are increasing $[4,5]$. Like any business, it should address potential failures that may be caused by various factors. These factors and the chain failure of companies can affect the economic situation of the company. Therefore, it is necessary for the state to pay attention to them. For businesses, inefficient management can lead to losses, in the worst-case bankruptcy [6]. In the case of the state, this can lead to a humanitarian crisis. Various tools can be used to prevent it. Innovation is currently one of the most important tools for maintaining and improving the development of the state economy and increasing competitiveness in the local and global environment [7]. A natural disaster will also affect an economically developed state, sometimes such a state will refuse humanitarian aid and will be able to deal with the situation on its own. Refusal was due to the bureaucratic obstacles and administrative failures in certain cases. It is therefore necessary that the humanitarian aid process be as appropriate as possible [8]. In order for these countries to be able to manage the crisis, it is necessary for them to have a transparent banking and financial system. Disclosure of specific banks and the financial system increases the stability of the system during crises and allows citizens to feel better about managing crises [9]. In the case of states, it is important to focus attention on their individual territorial units. As often, the problems in the state themselves are different in its 
parts. Therefore, a specific approach to all parts of the country is needed to manage the crisis $[10,11]$. There is also a different representation of companies in individual regions, which serve as part of the globalization mechanism for crisis prevention. Therefore, it is of course justified to focus on the composition of these enterprises and to invest in their development or in new enterprises that could improve the situation in the state [12]. In order to prevent a crisis or reduce its negative impact, it is necessary for the crisis management mechanism to be able to analyse all risks. It is the early identification of risks that have an impact on the environment that will allow appropriate measures to be taken when smaller resources need to be allocated [13].

The European Union, as a grouping of prosperous states, seeks to help states affected by the humanitarian crisis. They set aside funds to manage it and provide them in the form of humanitarian aid. However, Member States are different in terms of the level of their economy. They can be divided into three groups. The first group is composed of the most economically developed countries, which were adopted before 1995. The second group includes a large number of Central and Eastern European countries adopted in 2004. The last group are countries adopted after 2004 to the present [15]. The European Union is an organization of international crisis management. Its Member States set aside funds in the form of humanitarian aid for countries in need. Figure 1 shows the amounts of funds provided for the most recent year 2019. The amount of funds was converted from dollars, in which the individual amounts were displayed in euros. This conversion was based on the average dollar exchange rate against the euro for the year. The data were drawn from the OCHA Services database. For the states of Greece and Hungary, the amount was $€ 0$ due to the fact that no data were provided for the OCHA database. Therefore, these countries are not included in the comparison.

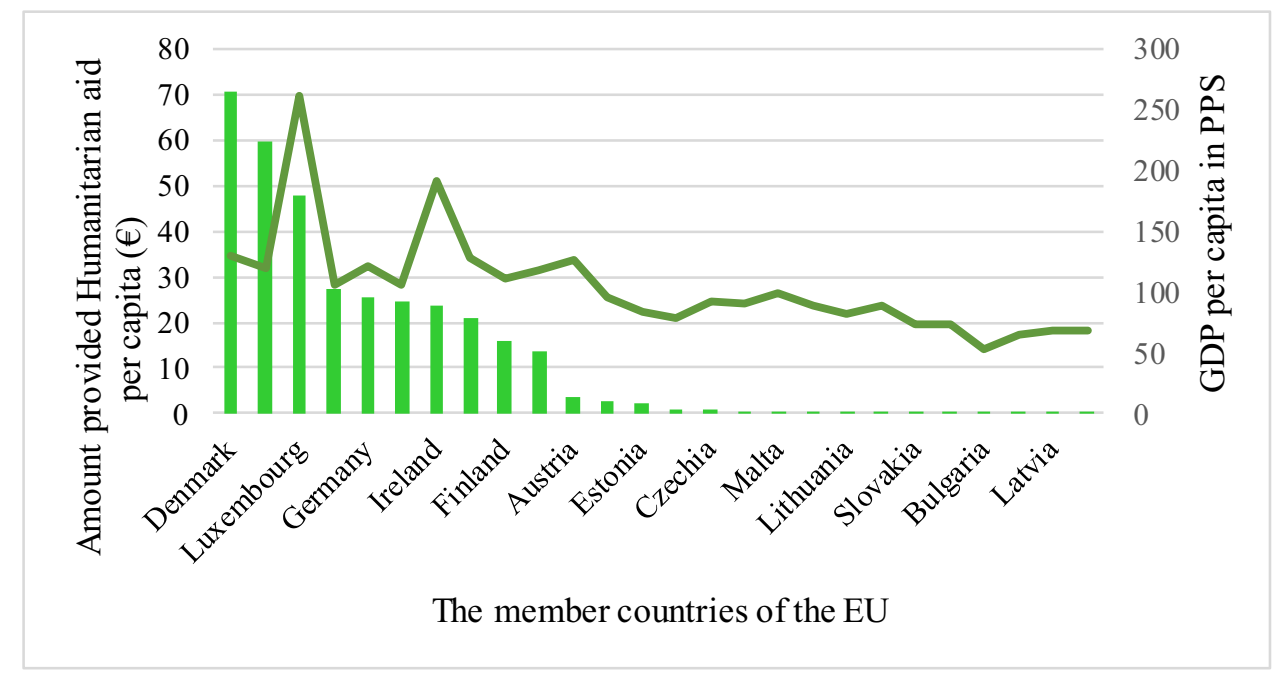

Fig. 1. The member countries of the EU and humanitarian aid and GDP provided per capita in 2019. $[14,15]$

The largest donor per capita is Denmark, which in 2019 contributed $€ 70.6$ per capita. Subsequently, Sweden was $€ 59.83$ per capita. The third was Luxembourg with a humanitarian aid amount of $€ 47.6$ per capita. Luxembourg also had the highest GDP per capita in PPS in that year. Slovakia was in 21 st place and provided $€ 0.05$ per capita that year. In order to find out whether there is a dependence between the funds spent and the GDP of individual states, we used the correlation function, which examines the given dependence in 2019. 


$$
\operatorname{Correl}(X, Y)=0,63
$$

The result points to a moderately strong correlation, i.e. the dependence between the donated amount and the GDP of the state is moderately strong. This means that GDP is not the main factor influencing the funding allocated to voluntary assistance. The main factor is the willingness of the state to help others in need.

\section{Humanitarian aid of Slovakia in the environment of globalization}

The coordinator and implementer of the provision of official humanitarian aid of the Slovak Republic abroad is the Ministry of the Interior of the Slovak Republic. The Ministry of the Interior of the Slovak Republic also provides activities related to humanitarian aid through the Crisis Management Section. Slovakia uses international humanitarian organizations, such as:

-The International Committee of the Red Cross

-United Nations Children's Fund

-the UN Refugee Agency

-International Organization for Migration

-United Nations World Food Programme

-Food and Agriculture Organization of the United Nations

-United Nations Development Programme, etc.

The new system Slovak humanitarian aid is aimed at increasing the reaction rate, greater flexibility and coordination, thus contributing to the overall improvement of targeting and results of the aid granted. The mechanism defines the competencies and responsibilities of central state administration bodies and expands the focus of Slovak humanitarian aid with new forms, creating opportunities for the involvement of other actors in its provision [17].

In 2019 , Slovakia contributed $€ 271,512$ to humanitarian aid. It is necessary to pay attention to what these funds are spent on. Figure 2 shows that $36.7 \%$ was provided for assistance in South Sudan and 37.5\% was in Yemen. $11 \%$ was set aside to help occupied the Palestinian territory, and $11 \%$ went to others that are not specified, assigned or cannot be fully determined for use. 


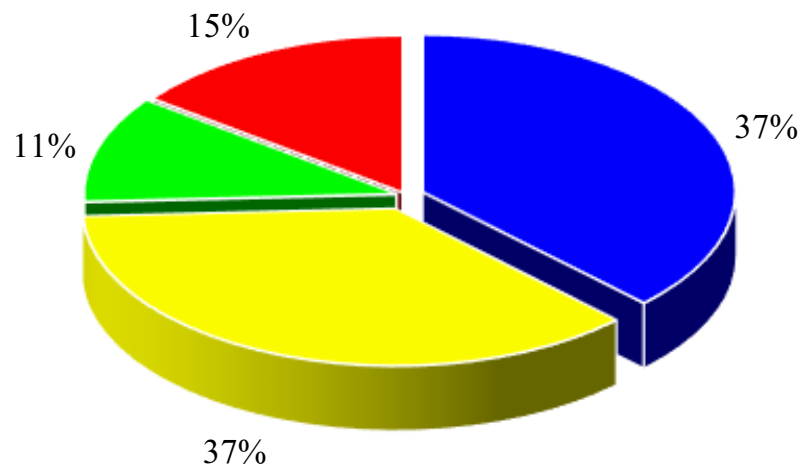

- Yemen $=$ South Sudan $\quad$ occupied Palestian territory - others

Fig. 2. Funding to affected countries. [18]

Figure 3 shows which sectors have been allocated funding from Slovakia in the framework of humanitarian aid. The largest part of $39.8 \%$ went to unspecified aid, or not exactly included. $36.7 \%$ was allocated to healthcare, $14.8 \%$ was allocated to coordination support services and $8.7 \%$ to food security.

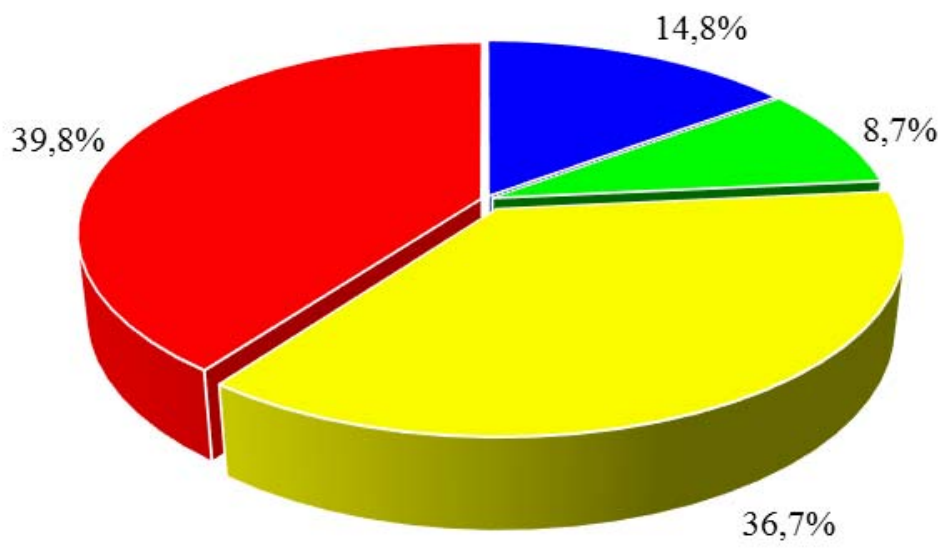

- Coordination and support services = Food Security " Health - others

Fig. 3. Funding by sector. [18]

Pointing out problematic parts of crisis situations allows crisis management to better understand the shortcomings. This information should serve as a source of information to address humanitarian crises more effectively and to address shortcomings in the way they learn from the past [19]. 


\section{Conclusions}

Crisis situations negatively affect the environment of states. Their range can disrupt a stable system in their environment. In the event of a major crisis, the state may have difficulty dealing with them. Just humanitarian aid from countries that are doing better, help them in the short term to overcome most problems. In this article, we focused on the assistance provided by the European Union as a crisis management organization. We calculated the spending of funds per capita and compared it with their GDP. We have found that their economic situation is not a major contributor to the humanitarian aid mechanism. In 2019, Slovakia was in 21st place among the countries being compared. It is also important to point out which countries and to which sectors Slovakia has allocated funds. It is such monitoring, that will make it possible to emphasize the importance of helping other states. Such comparisons and analyses should be carried out annually, with little result in clearly pointing out the most problematic areas of crisis and the countries most affected by crises.

This paper was supported by project VEGA 1/0755/18.

\section{References}

1. Commission of the European Communities (2007). Communication from the commission to the parliament and the council - towards a European consensus on humanitarian aid. Available on: https://ec.europa.eu/echo/files/policies/consensus/ acte_sk.pdf

2. Hinkle, D. E., Wiersma, W., Jurs, S. G. (2003). Applied statistics for the behavioral sciences. 5th ed. Boston: Houghton Mifflin, 2003.

3. Ristvej, J., Sokolova, L., Starackova, J., Ondrejka, R., Lacinak, M. (2017). Experiences with implementation of information systems within preparation to deal with crisis situations in terms of crisis management and building resilience in the Slovak Republic. International Carnahan Conference on Security Technology (ICCST).

4. Lovecek, T., Ristvej, J., Sventekova, E., Siser, A., Velas, A. (2016). Currently required competencies of crisis and security managers and new tool for their acquirement. Proceedings of the 3rd International Conference on Management Innovation and Business Innovation (pp. 3-8). 58.

5. Stofko, S., Stofkova, Z. (2011). The importance of education in personal property security area. In L.G. Chova, D.M. Belenguer, A.L. Martinez (Eds.). Proceedings of the $3^{\text {rd }}$ International Conference of Education and new Learning Technologies (EDULEARN) (pp. 5048-5051). Barcelona.

6. Kovacova, M., Kliestik, T., Valaskova, K., Durana, P., Juhaszova, Z. (2019). Systematic review of variables applied in bankruptcy prediction models of Visegrad group countries. Oeconomia Copernicana, 10(4), 743-772

7. Simickova, J., Buganova, K. (2019). Risk management as a tool for increasing the success of innovative projects. Proceedings of International Scientific Conference on The Impact of Industry 4.0 on Job Creation (pp. 397-404).

8. Charlotte, D. (2018). Failed cooperation in times of natural disasters: Explaining the rejection of humanitarian aid. International Relations of the Asia-Pacific, 20(2), 193223. 
9. Bouvard, M, Chaigneau, P., De Motta. (2015). Transparency in the Financial System: Rollover Risk and Crises. Journal of Finance. 70(4), 1805-1837.

10. Soltes, V., Stofkova, Z. (2016). Security as an aspect of the quality management in local self-government in age of globalization. Proceedings of the 16th International Scientific Conference on Globalization and its Socio-Economic (pp. 2060-2067). Rajecke Teplice, Slovak Republic.

11. Stofkova, J., Soltes, V., Maris, L. (2015). To the problem of information security within the local government. Proceedings of the 7th International Conference on Education and New Learning Technologies (pp. 6629-6635).

12. Stofkova Z., Hraskova, D. (2020) Company personnel policy as part of new management approaches in globalization. Proceedings of the 19th International Scientific Conference Globalization and Its Socio- Economic Consequences Sustainability in the Global-Knowledge Economy. 74. Rajecke Teplice, Slovak Republic.

13. Buganova, K., Luskova, M., Hudakova, M. (2013). Early warning systems in crisis management. Proceedings of the International Conference on Management Innovation and Business Innovation (pp. 218-233). 15.

14. Remeikiene, R., Belas, J. Kliestik. T., Smrcka, L. (2020). Quantitative assessment of dynamics of economic development in the countries of the European union. Technological and Economic Development of Economy. 26(4), 933-946.

15. OCHA Services, (2020). List of government donors. On-line, Available: https://fts.unocha.org/donors/overview.

16. EUROSTAT (2020). GDP and main components (output, expenditure and income) Online, Available: https://appsso.eurostat.ec.europa.eu/nui/show.do?dataset=nama_10_ gdp\&lang=en.

17. Ministry of Interior of the Slovak Republic (2020). Humanitarian Aid. On-line, Available https://www.minv.sk/?Humanitarna_pomoc.

18. Ocha Services (2020). Slovakia Government of. On-line. Available: https://fts.unocha.org/donors/93/summary/2020.

19. Mitasova, V., Soltes. V. (2017). Education of professionals for the international crisis management tasks' implementation. Proceedings of the 11th International Conference on Technology, Education and Development (pp. 6624-6629). 